\title{
PREVALENCE OF EPILEPSY AND SEIZURE DISORDERS AS CAUSES OF APPARENT LIFE- THREATENING EVENT (ALTE) IN CHILDREN ADMITTED TO A TERTIARY HOSPITAL
}

\author{
Alessandra Marques dos Anjos', Magda Lahorgue Nunes²
}

\begin{abstract}
Objective: To determine the prevalence and describe clinical characteristics of seizure disorders and epilepsy as causes of apparent life- threatening event (ALTE) in children admitted at the emergency and followed in a tertiary hospital. Method: Cross-sectional study with prospective data collection using specific guidelines to determine the etiology of ALTE. Results: During the study, $30(4.2 \%)$ children admitted to the hospital had a diagnosis of ALTE. There was a predominance of males $(73 \%)$ and term infants $(70 \%)$. Neonatal neurological disorders and neuropsychomotor development delay were found respectively in $13.4 \%$ and $10 \%$ of the cases. Etiological investigation revealed that $50 \%$ of the cases were idiopathic, and $13.4 \%$ were caused by epilepsy or seizure disorders. Although all patients had recurrent ALTE events, epilepsy had not been previously suspected. Conclusion: Epilepsy should be included in the differential diagnosis of ALTE, particularly when events are recurrent.
\end{abstract}

KEY WORDS: ALTE, sudden infant death syndrome, epilepsy.

\section{Prevalência de epilepsia e crises epilépticas como causa de eventos com aparente risco de vida (ALTE) em crianças internadas em hospital terciário}

Resumo - Objetivo: Determinar a prevalência e características clínicas de crises epilépticas e epilepsia como causa de eventos com aparente risco de vida (ALTE) em crianças atendidas na emergência e acompanhadas em hospital terciário. Método: Estudo transversal com coleta prospectiva de dados através de protocolo específico para identificação da etiologia de ALTE. Resultados: Foram diagnosticadas 30 crianças com ALTE perfazendo $4.2 \%$ das crianças internadas no período do estudo. Houve predominância no sexo masculino (73\%) e em neonatos a termo (70\%). História prévia de doenças neurológicas no período neonatal e atraso no desenvolvimento neuropsicomotor ocorreram respectivamente em $13.4 \%$ e $10 \%$ dos casos. A investigação etiológica identificou $13.4 \%$ dos casos relacionados a epilepsia ou crise convulsivas e $50 \%$ idiopáticos. Apesar destes pacientes terem apresentados episódios recorrentes em nenhum caso havia a suspeita prévia de epilepsia. Conclusão: Ao investigar pacientes com ALTE a possibilidade do diagnóstico de epilepsia deve ser fortemente considerada principalmente nos casos recorrentes.

PALAVRAS-CHAVE: ALTE, síndrome da morte súbita do lactente, epilepsia.

The "National Institutes of Consensus Development Conference of Infantile Apnea and Home Monitoring" conducted by the National Institute of Health of the United States in 1986 defined an apparent life-threatening event (ALTE) as an event that is frightening to the observer and that is characterized by some combination of the following factors: central or obstructive apnea, color change (cy- anotic, pallid or plethoric), change in muscle tone (hypotonia, hypertonia), choking, or gagging'. Previously known as near-miss sudden infant death syndrome, the denomination was changed because of its very close association with sudden infant death syndrome (SIDS), which was not confirmed in later studies ${ }^{1-3}$. The incidence of ALTE varies substantially in the literature. Brooks found an inci-

\footnotetext{
Division of Neurology and Clinical Neurophysiology Laboratory, Hospital São Lucas, Pontificia Universidade Catolica do Rio Grande do Sul (PUCRS), Porto Alegre RS, Brazil: 'Pediatric Neurologist Master's Degree in Medicine and Health Sciences, PUCRS; 'Associate Professor, Neurology, School of Medicine, PUCRS. This study was partially funded by a CAPES scholarship to one of the authors (AMA) and a CNPq grant for Research Productivity $\left(n^{\circ} 300364 / 2004-0\right)$ to the other author (MLN).
}

Received 31 October 2008, received in final form 19 March 2009. Accepted 20 May 2009. 
dence of $0.5 \%$ to $6 \%$ in a pediatric population ${ }^{2}$. Later studies found an incidence of $0.6-0.8 \%$ in infants seen in British emergency departments, $2.27 \%$ among children hospitalized in France, and $0.05 \%$ in Sweden ${ }^{4-6}$. Population studies reported that ALTE was diagnosed in $2.46 / 1000$ live births in Tyrol and in 9.4/1000 in New Zealand ${ }^{7,8}$. Differences may be assigned to variations in study populations, designs (population vs. institutional) and, particularly, inclusion criteria. ALTE should be classified as a symptom or main complaint and never as a final diagnosis'. No treatment is available for ALTE specifically; therefore, the purpose of clinical evaluations should be the detection of the underlying cause of the event, which will define outcome and prognosis. Cases that remain undiagnosed after initial clinical evaluation, complementary tests, and follow-up of clinical progression after hospital discharge are classified as idiopathic ${ }^{3,9}$. The severity of the event is determined according to clinical history, clinical examination and analysis of risk factors. The classification suggested by the Sudden Death Committee of the Latin American Pediatric Association (ALAPE), for example, provides a basis for diagnosis and event management ${ }^{9,10}$.

ALTE may be the first sign of an epileptic seizure. Diagnosis is often difficult because interictal EEG is usually normal or shows unspecific changes, and gastroesophageal reflux may mimic this event ${ }^{11}$. A retrospective analysis of cases showed that ictal EEG is the standard criterion to confirm diagnosis. However, potentially epileptogenic structural changes seen in neuroimaging studies may suggest this diagnosis when only interictal EEG recordings are available.

The aim of this study was to determine the prevalence and describe clinical characteristics of epilepsy and other seizure disorders as causes of ALTE in children seen at the emergency department of a tertiary hospital.

\section{METHOD}

A cross-sectional prospective study was performed to determine the prevalence and the characteristics of epilepsy and seizure disorders as a cause of ALTE in children seen in an emergency service and admitted to the São Lucas Hospital for evaluation from September 2004 to March 2006. Patients included in the study were followed up until September 2006 to determine recurrence and morbidity.

Inclusion criteria were: age 0 to 24 months; and clinical signs and symptoms compatible with the definition of ALTE '. Patients were included consecutively as they were seen in the emergency service of the São Lucas Hospital of the School of Medicine of Pontificia Universidade Catolica do Rio Grande do Sul (PUCRS), Porto Alegre, Brazil.

Patients were excluded from the study if informed consent was not provided, or if clinical criteria for the diagnosis of ALTE were not met.
Before data collection, the staff at the pediatric emergency service received instructions on how to identify patients with ALTE according to the ALAPE guidelines ${ }^{10}$. When the patient arrived in the emergency service, a neurological evaluation was requested. If ALTE was confirmed, one of the authors (AMA) was notified and started the procedures for the first 24 hours of hospitalization.

Still in the emergency service, routine tests for ALTE were performed: $C B C$, electrolytes, glucose, blood and urine cultures, chest X-ray and electrocardiogram. Patients were referred to pediatric gastroenterology, pulmonology or cardiology teams if necessary, and specific tests, such as $\mathrm{pH}$ monitoring, echocardiography, electroencephalography, polysomnography, and video-EEG, were performed when requested. One of the authors (AMA) monitored all the evaluation procedures during hospitalization and followed all the steps prescribed by ALAPE ${ }^{10}$. Cases were classified according to their severity as: minor ALTE, when reversion of clinical conditions was spontaneous or a consequence of mild stimulation; or major ALTE, when the event reversed only after vigorous stimulation or cardiorespiratory resuscitation. The presence or absence of risk factors was also assessed ${ }^{10}$.

In case of recurrent ALTE, 24-hour EEG recordings were obtained during hospitalization using a holter-EEG. All recordings were interpreted by the same author (MLN). As it is a relatively new test in our environment, an informed consent term was signed by a parent or guardian when it was requested.

After hospital discharge, infants were followed up in the Pediatric Neurology or Pediatrics outpatient service in the same hospital to evaluate clinical progression (recurrence and morbidity). Phone contacts were made in case follow-up was conducted at another healthcare service.

Study variables were sex, age, gestational age, nutritional status at birth, neonatal neurological problems, medical history, neurological examination at hospital admission, maternal history of psychiatric treatment, family history of ALTE or sudden infant death syndrome (SIDS), maternal smoking, event severity, recurrence, vaccination before event, and period of occurrence in the sleep-wake cycle. The event was classified as symptomatic (defined etiology) or idiopathic according to findings. Study outcomes were recurrence, death due to known cause, or unexplained sudden death.

The diagnosis of epilepsy was based on clinical history, event recurrence, and electroencephalogram findings.

An EXCEL database was used to store data, and the SPSS statistical software was used for data analysis. Frequencies, means, standard deviations and medians were described. For all variables described, 95\% confidence intervals were calculated. Qualitative variables were analyzed using the Fisher exact test. Clinically relevant variables were included in the logistic regression model to detect possible confounding factors.

This study was approved by the review board of the institution where it was conducted (Ethics Committee of PUCRS). 


\section{RESULTS}

According to diagnostic criteria, 30 infants and children aged 1 day to 18 months (median=3.6 months, SD=5.1 months; median=2 months) were included in the study; $80 \%$ of the events occurred before 3 months of life. One patient with a history of perinatal asphyxia had an ALTE on the first day of life. The prevalence of ALTE was $4.2 \%$ $(95 \% \mathrm{Cl}, 2.9-5.9 \%)$ of the pediatric patients seen in the emergency service during the study. Events were all observed by parents. Most of the infants were boys (73.3\%) born at term $(70 \%)$ with adequate weight for gestational age (86.7\%). Three children had a diagnosis of neonatal neurological problems: one had meningitis, one, an encephalocele, and one, ischemic hypoxic encephalopathy. Comorbidities before hospitalization were reported for 5 infants: bronchopulmonary dysplasia, congenital hip dysplasia, swallowing disorders, bronchiolitis, and congenital infection. Before hospitalization, neuropsychomotor development of three patients was delayed according to chronological age or adjusted gestational age for premature infants.

Event classification revealed 29 cases of minor ALTE $(97 \%)$ and only one of major ALTE. Most events (83\%) occurred during the day, when the patient was awake.

The analysis of etiology showed a predominance of idiopathic cases (50\%). ALTE was caused by epilepsy in three patients, and by neonatal seizures in one.

\section{Case 1}

A 2-month-old female infant had several ALTE a day for 15 days; no triggering factors or perinatal events. Positive family history for epilepsy was reported. Clinical examination revealed neuropsychomotor developmental delay and congenital anomalies of the feet. Initial laboratory tests and interictal EEG were normal. EEG monitoring for 24 hours detected ALTE, which corresponded to focal paroxysmal activity in the left rolandic region with some propagation to temporal areas (Figure). Brain MRI suggested a hypoxic-ischemic lesion. Seizures were controlled after the introduction of carbamazepine.

\section{Case 2}

A 11-month-old female infant. Pregnancy was classified as risky, and there were several bleeding events during gestation. Birth was preterm at 27 weeks, and birth weight was 845 grams. Apgar scores were not reported. Patient had a history of admissions to neonatal ICU, prolonged mechanical ventilation, use of nasogastric tube due to swallowing disorder, and blood transfusions due to anemia. The patient had several ALTE after extubation, but no triggering factor was detected. Examination revealed overall delay in neuropsychomotor development. Family history of epilepsy was positive. Chest X-ray showed residual atelectasis. Interictal EEG was normal; 24-hour EEG showed epileptogenic activity in right frontotemporal areas followed by slowing of background activity at the time of seizure. Brain MRI was suggestive of hypoxicischemic lesions. Seizures were controlled with the introduction of carbamazepine.

\section{Case 3}

A 3-month-old male infant with encephalocele corrected on the first day of life and neuropsychomotor delay; admitted to investigation because of recurrent ALTE observed in the last few days. Interictal EEG showed asymmetrical background activity, disorganized in the left side,

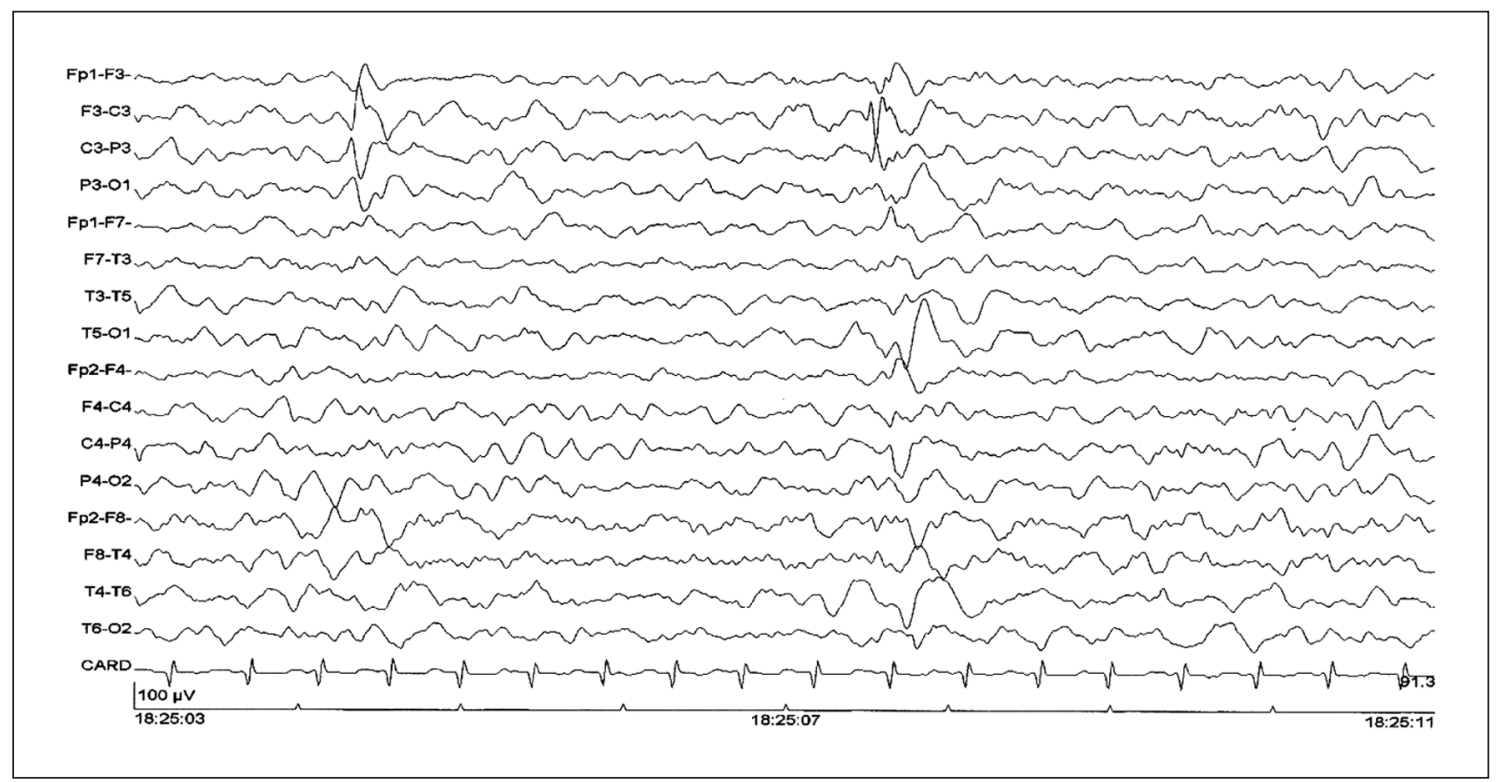

Figure. EEG with focal paroxysmal activity in the left rolandic region with some propagation to temporal areas. 
and left posterior epileptogenic activity with frequent generalizations. Patient was started on antiepileptic drugs (valproic acid) and latter was maintained with a combination of carbamazepine and topiramate, that reduced the frequency of seizures.

\section{Case 4}

A $2^{\text {nd }}$ day of life -female newborn whose mother reported that prenatal follow-up was uneventful; infant had two loops of cord around the neck at delivery and ecchymotic mask. The first event occurred at 18 hours of life and was classified as major ALTE because cardiorespiratory resuscitation and endotracheal intubation were necessary. Interictal EEG showed bilateral frontal epileptogenic activity; brain CT scan showed frontotemporal hypodense areas and small areas of secondary hemorrhage. Events were controlled with the use of phenobarbital.

According to a current diagnostic scheme form International League against Epilepsy (ILAE), cases 1, 2 and 3 were classified as symptomatic focal epilepsy, and case 4 , as epileptic seizure that does not require a diagnosis of epilepsy (single seizure or burst)".

The evaluation of qualitative variables in association with recurrence, as well as with idiopathic cause (as the majority of cases were idiopathic) showed statistically significant difference only for gestational age: when term and preterm infants were compared, ALTE recurrence was greater among those born at term $(71.4 \% \times 28.6 \% \mathrm{p}=0.04)$. However, this result did not reach significance after multivariate analysis. There were also no significant differences between study variables and idiopathic etiology.

Follow-up after hospital discharge lasted from 7 to 24 months, and mean time was 17.6 months ( $\mathrm{SD}=4.8$ months; median - 19 months).

Recurrence of epileptic seizures was reported in the case of refractory epilepsy (patient 3). However, events became less intense with the use of anticonvulsant drugs and no longer met the clinical criteria to be diagnosed as ALTE.

\section{DISCUSSION}

This study described the clinical characteristics, etiological assessment, and follow-up of patients with ALTE, primarily focused on cases of epilepsy and seizure disorders. Differently from other studies in the literature, data collection and patient follow-up were prospective and started at patient arrival in the emergency department. Moreover, specific guidelines were used for the investigation of ALTE ${ }^{10}$. Previous studies conducted by the same authors were retrospective and based on the review of patient records because no definite guidelines for patient evaluation were available in the literature at that time ${ }^{12,13}$.

Most classical studies about ALTE are based on retrospective data collection, and only a few are prospective $e^{5,7,14,15}$.
Prospective data collection using specific guidelines may increase diagnostic reliability.

The prevalence of $4.2 \%$ of ALTE among the study population is similar to the value described by Brooks ${ }^{2}$. However, it is greater than the prevalence found in British emergency services $(0.6-0.8 \%)$ and in a population study conducted in Tyrol (2.46/1000 live births) $)^{4,5,7}$. Emergency department staff were trained and motivated to detect patients with this condition, which may explain this difference'.

Epidemiological studies found that the most frequent cause of ALTE is gastroesophageal reflux disorder, followed by respiratory infections and seizures ${ }^{4,5,13-21}$. Epilepsy or epileptic seizures were the third most frequent cause in our study.

Mechanisms that may explain the association between ALTE and epilepsy are based on three factors: heart rate variability during sleep or seizures, the role of apnea as a clinical sign of seizure, and the effect of the sleep-wake cycle on epilepsy ${ }^{22}$.

Autonomic changes in patients with epilepsy, detected in both ictal and interictal tests, have been reported in previous studies, most of which were conducted with adults. Tachycardia seems to be the most frequent finding ${ }^{23,24}$. Heart rate is controlled by sympathetic and vagal efferent activity towards the sinus node, which is modulated by central mechanisms (brainstem) and peripheral oscillators ${ }^{25}$. In children with partial epilepsy, an autonomic change takes place during REM sleep, and heart rate variability decreases, which may be associated with the genesis of sudden death in epilepsy ${ }^{26}$.

Apnea as a seizure event has been classified as a type of subtle seizure of newborns; the event may last up to 2 or 3 minutes, but there are no simultaneous changes in heart rate ${ }^{27}$. Apnea may also be a clinical sign of a seizure originated in the temporal lobe. The discharges that originate deeply in the nervous system and that involve limbic structures may have this clinical presentation, which may somehow explain why practically no abnormal findings are identical in interictal EEG ${ }^{28,29}$.

The association or possible effect of the sleep-wake cycle in epilepsy shows that seizures originated in the temporal lobe are predominant during wakefulness ${ }^{30}$. This is in agreement with these study findings, which showed that ALTE was predominant during wakefulness.

Continuous EEG monitoring of the patients followed up in this study was essential to obtain ictal recordings of the event and to determine that ALTE was a sign of epilepsy. Event recurrence was high both before and during hospitalization, particularly among the neurological cases. During the etiological investigation of ALTE, first seizures and epilepsy should be included in the differential diagnosis and ictal recordings are an important tool for confirmation of the diagnoses ${ }^{12,22,29}$. However in cases were 
only interictal EEGs were available but with consistent epileptogenic alterations and neuroimage studies are compatible with central nervous system lesions, a trial with antiepileptic drugs is suggested ${ }^{22}$. If a positive response is achieved, as it happened with cases 3 and 4 a diagnosis of epileptic seizures is the more probable.

In conclusion, we have found that the prevalence of ALTE in this study population, as well as the frequency of epilepsy cases, was similar to those reported in the literature. The diagnosis of epilepsy should be initially suspected in cases of recurrent ALTE and in infants with ALTE and neurological disorders or with associated neuropsychomotor delay.

\section{REFERENCES}

1. National Institutes of Consensus Development Conference of Infantile Apnea and Home Monitoring, 1986. Pediatrics 1987;79:292-299.

2. Brooks JG. Apparent life-threatening events and apnea of infancy. Clin Perinatol 1992;19:809-838.

3. De Wolfe CC. Apparent life- threatening event: a review. Pediatr Clin N Am 2005;52:1127-1146.

4. Gray C, Davies F, Malyneux E. Apparent life threatening events presenting to a pediatric emergency department. Pediatr Emerg Care 1999; 15:195-199.

5. Davies F, Gupta R. Apparent life threatening events in infants presenting to an emergency department. Emerg Med J 2002;19;11-16.

6. Wennergren G, Milerad J, Lagercrantz H, et al. The epidemiology of sudden infant death syndrome and attacks of lifelessness in Sweden. Acta Paediatr Scand 1987;76:898-906.

7. Kiechl-Kohlendorfer U, Hof D, Peglow UP, Traweger-Ravanelli B, Kiechl S. Epidemiology of apparent life threatening events. Arch Dis Child 2004;90:297-300.

8. Mitchell EA, Thompson JMD. Parental reported apnoea, admissions to hospital and sudden infant death syndrome. Acta Paediatr 2001;90: 417-422.

9. Kahn A. Recommended clinical evaluation of infants with an apparent life-threatening event. Consensus document of the European Society for the Study and Prevention of Infant Death;2003. Eur J Pediatr 2004;163:108-115.

10. Rivarola MR, Nunes ML, Comitê de Síndrome da Morte Súbita do Lactente da Associação Latinoamericana de Pediatria (ALAPE). Consenso para o manejo e seguimento de pacientes com episódios de possível ameaça a vida (ALTE) e abordagem do diagnóstico diferencial com primeira crise convulsiva. J Epilepsy Clin Neurophysiol 2007;13:51-57.

11. Engel J Jr. A proponed diagnostic scheme for people with epileptic sei- zures and with epilepsy: report of the ILAE task force on classification and terminology. Epilepsia 2001;42:796-803.

12. Nunes ML, Appel CC, Costa JC. Apparent life threatening episodes as the first manifestation of epilepsy. Clin Pediatr 2003;42:19-22.

13. Nunes ML, Costa JC, Ferreira CP, Garcia CC, Marques FC, Spolidoro JVN. Patologias associadas e prognóstico de eventos com aparente risco de vida (ALTE). J Pediatr (Rio J) 1999;75:55-58.

14. Rivarola MR, Jenik A, Kenny P, Agosta G, Ruiz AL, Gianantonio CA. Evento de aparente amenaza a la vida. Experiencia de un enfoque pediátrico interdisciplinario. Arch Argent Pediatr 1995;93:85-91.

15. Kurz R, Kerbl R, Reiterer F, et al. The role of triggers in apparent lifethreatening events (ALTE). J Sudden Infant Death Synd Infant Mortality 1997;2:3-12.

16. McGovern MC, Smith MBH, Causes of apparent life threatening events in infants: a systematic review. Arch Dis Child 2004;89:1043-1048.

17. Laisne C, Rimet $Y$, Poujol A, et al. A propos de cent malaises du nourissons. Ann Pédiatr (Paris) 1989;36:451-454.

18. Sheikh S, Stephen T, Frazer A. Apparent life threatening events in infants. Clin Pulm Med 2000;7:81-84.

19. Tal Y, Tirosh E, Even L, Jaffe M. A comparison of the yield of a 24 h versus $72 \mathrm{~h}$ hospital evaluation in infants with apparent life threatening events. Eur J Pediatr 1999;158:954-954.

20. Tsukada K, Kosuge N, Hosokawa M, Hasegawa T, Wada K, Arakawa M. Etiology of 19 infants with apparent life threatening events: relationship between apnea and esophageal dysfunction. Acta Paediatr Jpn 1993;35:306-310.

21. Veereman-Wauters G, Bochner A, Caillie-Bertrand M. Gastroesophageal reflux in infants with a history of near-miss sudden infant death. J Ped Gastr 1991;12:319-323.

22. Heinessen L, Dusser A, Nouirygat V, et al. Epilepsy presenting as lifethreatening events in infants. Arch Pediatr 2000;7:955-960.

23. Frysinger RC, Harper RM. Cardiac and respiratory correlations with unit discharge in epileptic human temporal lobe. Epilepsia 1990;31:162-171.

24. Galimberti CA, Marchioni E, Barzizza F, Manni R, Sartori I, Tartara A. Partial epileptic seizures of different origin variably affect cardiac rhythm. Epilepsia 1996;37:742-747.

25. Malliani A, Pagani M, Lombardi F, Cerutti S. Cardiovascular neural regulation explored in frequency domain. Circulation 1991;84:1482-1492.

26. Ferri R, Curzi-Dascalova L, Arzimanoglou A, et al. Spectral analysis of heart rate variability during sleep in children with partial epilepsy. J Sleep Res 2002;11:153-160.

27. Lombroso CT. Neonatal seizures: a clinician's overview. Brain Dev 1996;18:1-28.

28. Singh B, Al Shahwan AS, Al Deeb SM. Partial seizures presenting as life-threatening apnea. Epilepsia 1993;34:901-903.

29. Hewertson J, Poets CF, Samuels MP, Boyd SG, Neville BGR, Southall DP. Epileptic seizure-induced hypoxemia in infants with apparent lifethreatening events. Pediatrics 1994;94:148-156.

30. Dinner DS. Effect of sleep on epilepsy. J Clin Neurophysiol 2002;19: 504-513. 